\title{
Imposed Deformations Measured on a Real Integral Structure: New Airport Terminal Barajas, Madrid, Spain
}

\author{
Tobias Petschke ${ }^{1}$; Eduardo Garcia ${ }^{2}$; Alejandro Pérez ${ }^{3}$; and Hugo Corres ${ }^{4}$
}

\begin{abstract}
Experimental research on imposed deformation is generally conducted on small-scale laboratory experiments. The attractiveness of field research lies in the possibility to compare results obtained from full-scale structures to theoretical predictions. Unfortunately, measurements obtained from real structures are rarely described in literature. The structural response of integral edifices depends significantly on stiffness changes and constraints. The New Airport Terminal Barajas in Madrid, Spain provides investigators with large integral modules, partially post-tensioned concrete frames, cast monolithically over three floor levels with an overall length of approximately $80 \mathrm{~m}$. The field campaign described in this article explains the instrumentation of one of these frames, focusing on the influence of imposed deformations such as creep, shrinkage, and temperature. The applied monitoring equipment included embedded strain gauges, thermocouples, hand-held mechanical strain gauge measurements, and simple displacement measurements. Data were collected throughout construction and during two years of service. A complete data range of five years is presented and analyzed. Using a simple approach, the results are compared to predict the longterm shortening of this concrete structure. Both analytical and experimental results are discussed.
\end{abstract}

Āuthor keywords: Constructed; Concrete; Creep; Post-tensioning; Strain; Long-term deformations; Performance; Serviceability; Temperature; Measurements.

\section{Introduction}

Integral buildings are large structures made with a reduced number of expansion joints, or even none at all. The construction of such buildings is not a common practice, because most applicable building codes provide rules that only allow for omittance of imposed deformations during a serviceability assessment if expansion joints are provided in the ranges of $30^{\wedge}-0 \mathrm{~m}$ [Ministerio de Vivienda (2006),
European Committee for Standardization (CEN) (2004), and the American Concrete Institute (ACI) (2008)].

In his thesis, Camara (1988) pointed out the stiffness dependence of the imposed deformations during a structural analysis. In a conventional serviceability assessment, the forces caused by imposed deformations are commonly overestimated because linear numeric procedures are used. Therefore, Pfeiffer (2004) developed a nonlinear analysis program to take into account additional axial strains and imposed deformations under the consideration of stiffness changes during serviceability checks. However, it is not all a question of stiffness changes; sometimes it all just depends on a realistic assumption of the imposed deformation's magnitude. Koch and Plotzel (2001) confirmed, through strain and temperature measurements obtained from the Nesenbach Valley Bridge, that it is possible to create jointless structures larger than $40 \mathrm{~m}$ even under constrained conditions. They also could show, with the recorded data, that there is a significant difference between shrinkage measured on a specimen in the laboratory and the values obtained from an on-site specimen.

Hock et al. (1986) instrumented a building with typical dimensions not exceeding jointless modules of more than $24 \mathrm{~m}$. The measurements provided investigators with the evidence that in the building's slab, the temperature-imposed axial deformation was significantly more important than the temperature-imposed curvature. Iskander et al. (2001) described an instrumentation conducted to assess the serviceability and durability of a damaged car-park compound. They also reported about the problems they were facing during instrumentation and data collection. Later, Aboumoussa and Iskander (2003) analyzed the thermal movements measured in the field study by Iskander et al. They found out that the generally used coefficient of concrete's thermal expansion is appropriate 


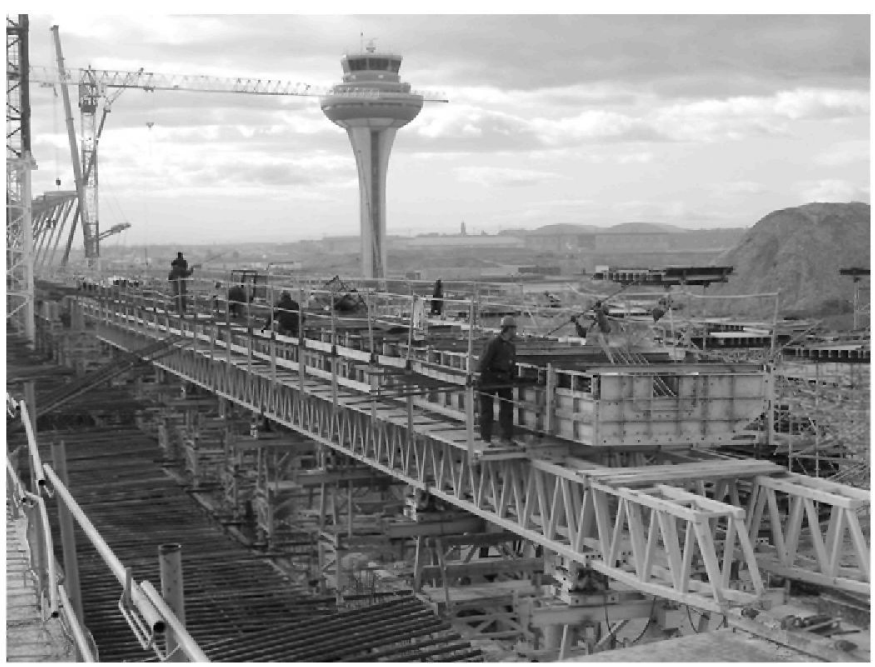

Fig. 1. Satellite Building T4 of the New Airport Terminal Barajas during construction (photograph by Tobias Petschke)

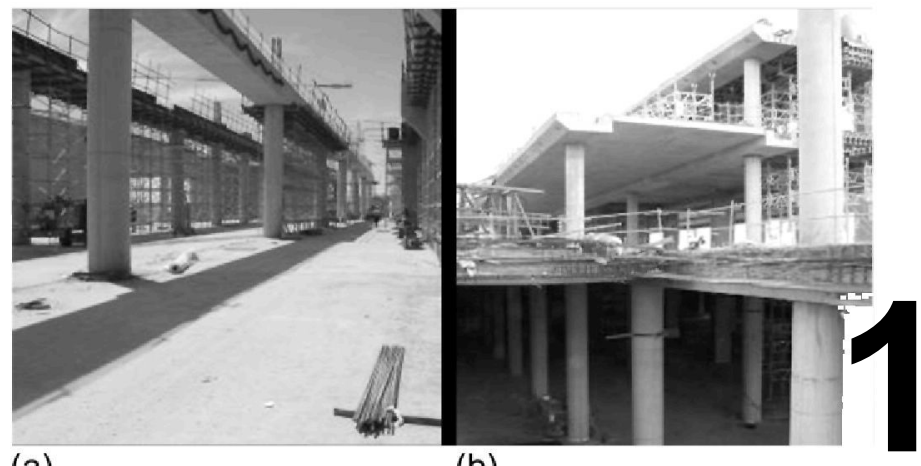

(a)

(b)

Fig. 2. Concrete supporting structure for the New Airport Terminal Barajas: (a) level N-1; (b) view of all three instrumented floors (photographs by Tobias Petschke) for the analysis of open buildings, but that restraints imposed by monolithical construction can have a significant influence on the building's movements. This was also found by Iqbal (2007), who instrumented a series of operating parking facilities. Six of these facilities were precast/prestressed and four were post-tensioned. He proposed the introduction of an additional factor to the equation of thermal expansion to account for structural influence. Forth et al. (2003) conducted another remarkable study on a full-scale sevenstory building in a testing facility.

Unfortunately, it is practically impossible to simulate the combination of all actions to which a real structure is exposed. Nonetheless, such studies provide valuable data on the behavior of real structures. Most of the field campaigns are of limited duration, and are usually monitored either during construction or in service.

The study described here deals with the effects of imposed deformations in an integral structure: the Satellite Building of the New Airport Terminal Barajas, which has been monitored throughout a period of five years from construction into service. The building is shown during construction in Fig. 1. Its overall length is approximately $1 \mathrm{~km}$ with a substructure consisting of post-tensioned concrete frames evenly divided approximately every $80 \mathrm{~m}$ by expansion joints. A symmetrical frame, which forms part of this substructure, was selected and instrumented in its extremes over three stories. It was, furthermore, the aim of this research to find out whether the structure's behavior can be efficiently predicted with common methods of analysis such as those used in daily practice.

In Fig. 2(a), the frame of the lowest level is shown with the formwork partially removed. Fig. 2(b) displays a more advanced state of construction, showing all three levels of the structure. The frames support prefabricated hollow-core slabs in the transversal direction that do not contribute to the structure's longitudinal stiffness. The frames were post-tensioned and connected monolithically with the supporting columns throughout all three floor levels. Each frame consists of four 18-m-long spans and additional cantilevers at the extremes where the joints were placed in the adjacent fields. The instrumented frame is symmetric with short-end cantilevers; its overall length is $77.4 \mathrm{~m}$, as shown in Fig. 3. The frames were cast using a concrete that had a compression strength of $f_{c}=40 \mathrm{MPa}$ and a passive reinforcement with a yield strength of $f_{y}=500 \mathrm{MPa}$. The construction procedure required finishing all the

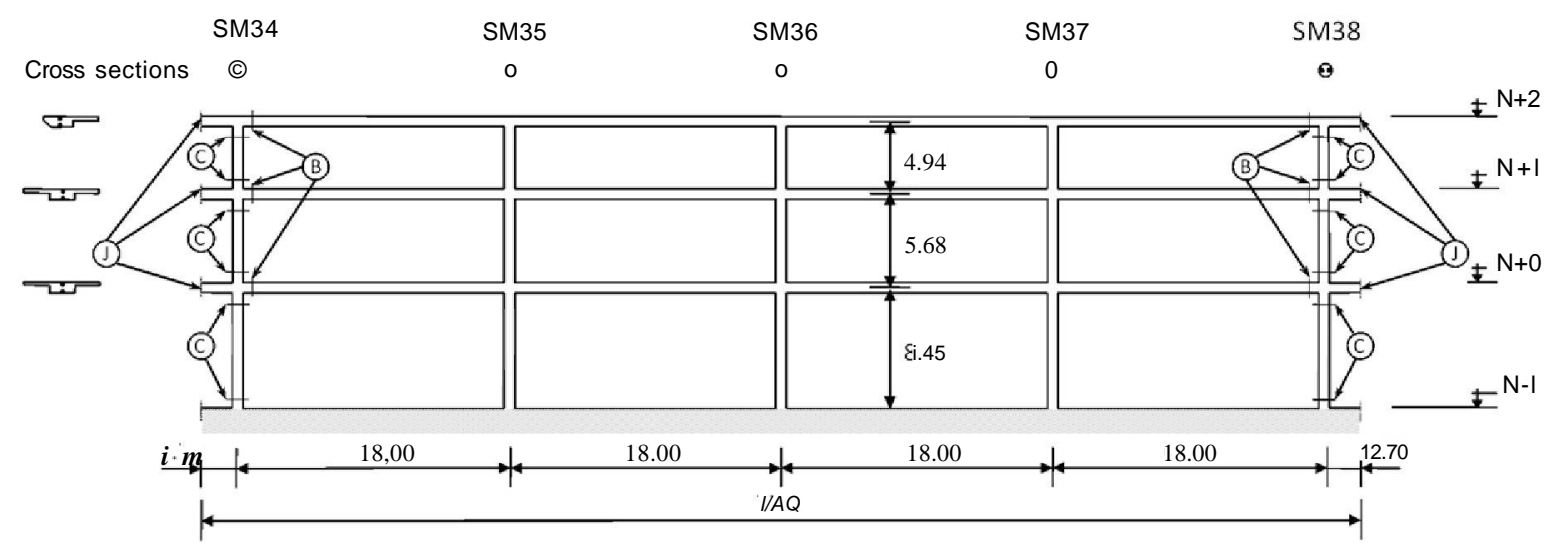

B Instrumented beam sections

C Instrumented column sections

$\checkmark$ Instrumented expansion joints

Fig. 3. Scheme indicating the location of the instruments 
columns of one floor before casting its corresponding beam. After removing the beams' formwork, prestressing was applied; then the slabs could be cast and construction of the next level's frame could begin.

The main construction phases concerning this measurement campaign are displayed with their dates in Table 1. The columns' diameter and reinforcements are shown in Table 2. The passive reinforcement data of the beams is displayed in Table 3 and a detailed description of their geometry in Fig. 4. The post-tensioning of the beams consisted of two tendons with a cross-section area of $140 \mathrm{~mm}^{2}$ formed by 15 seven-wire strands. The prestressing steel applied had a tensile strength of $/,=1,860 \mathrm{MPa}$. The tendons followed a parabolic spline, which had its maximum turning points $0.085 \mathrm{~m}$ from the extreme fiber of the upper reinforcement above the columns, and its minimum turning points at $0.135 \mathrm{~m}$ above the lower extreme fiber of the concrete cross section in the center of the spans.

Table 1. Construction Phases with Date

\begin{tabular}{lc}
\hline Process & Date (month/day/year) \\
\hline Concreting column SM34 N-1 & $5 / 28 / 2002$ \\
Concreting beam SM34-38 N+0 & $7 / 9 / 2002$ \\
Removing formwork & $7 / 15 / 2002$ \\
Prestressing beam SM34-38 N+0 & $7 / 16 / 2002$ \\
Concreting slab N+0 & $8 / 1 / 2002$ \\
Concreting column SM 34 N+0 & $8 / 20 / 2002$ \\
Concreting beam SM34-38 N+1 & $8 / 29 / 2002$ \\
Prestressing beam SM34-38 N+1 & $9 / 5 / 2002$ \\
Concreting slab N+1 & $9 / 20 / 2002$ \\
Concreting column SM 34 N+1 & $10 / 3 / 2002$ \\
Concreting beam SM34-38 N+2 & $10 / 26 / 2002$ \\
Prestressing beam SM34-38 N+2 & $10 / 30 / 2002$ \\
Concreting slab N+2 & $11 / 15 / 2002$ \\
Roof structure finished & $7 / 30 / 2003$ \\
Structure air-conditioned & $2 / 19 / 2006$ \\
\hline
\end{tabular}

Table 2. Column Reinforcement

\begin{tabular}{lcccccc}
\hline Level & Diameter & SM34 & SM35 & SM36 & SM37 & SM38 \\
\hline $\mathrm{N}+1$ & $0.80 \mathrm{~m}$ & 16032 & 16032 & 16025 & 16025 & 16025 \\
$\mathrm{~N}+0$ & $0.80 \mathrm{~m}$ & 12025 & 12032 & 12032 & 12032 & 12025 \\
$\mathrm{~N}-1$ & $1.00 \mathrm{~m}$ & 14025 & 14025 & 22025 & 22025 & 14025 \\
\hline
\end{tabular}

Table 3. Principal Reinforcement at Positive and Negative Moment Regions of the Frame's Beams for All Three Levels

\begin{tabular}{ccccccc}
\hline Level & Layer & Supplement & $\mathrm{M}(-)$ & Length & $\mathrm{M}(+)$ & Length \\
\hline $\mathrm{N}+2$ & $\mathrm{~A}_{\mathrm{s} 2}\left(\mathrm{~cm}^{2}\right)$ & & 10032 & $8 \mathrm{~m}$ & 11016 & $12 \mathrm{~m}$ \\
& & & 8032 & $6 \mathrm{~m}$ & & \\
& Asi $\left(\mathrm{cm}^{2}\right)$ & & 8016 & $8 \mathrm{~m}$ & 8025 & $12 \mathrm{~m}$ \\
$\mathrm{~N}+1$ & $\mathrm{~A}_{\mathrm{s} 2}\left(\mathrm{~cm}^{2}\right)$ & First layer & 8032 & $8 \mathrm{~m}$ & 8016 & $12 \mathrm{~m}$ \\
& & & 7032 & $6 \mathrm{~m}$ & & \\
& & \multirow{2}{*}{ Second layer } & 8025 & $8 \mathrm{~m}$ & & \\
& & & 4025 & $6 \mathrm{~m}$ & & \\
$\mathrm{~N}+0$ & $\mathrm{~A}_{\mathrm{s} 1}\left(\mathrm{~cm}^{2}\right)$ & & 8016 & $8 \mathrm{~m}$ & 8025 & $12 \mathrm{~m}$ \\
& $\mathrm{~A}_{\mathrm{s} 2}\left(\mathrm{~cm}^{2}\right)$ & & 8032 & $8 \mathrm{~m}$ & 8016 & $12 \mathrm{~m}$ \\
& & & 7032 & $6 \mathrm{~m}$ & & \\
& Asi $\left(\mathrm{cm}^{2}\right)$ & 8016 & $8 \mathrm{~m}$ & 8025 & $12 \mathrm{~m}$ \\
\hline
\end{tabular}

The prestressing force applied was Po $=2,990 \mathrm{kN}$ per tendon, with a consideration of 5-mm anchorage slip.

\section{Instrumentation}

The instrumentation consisted of strain, temperature, and displacement measurements. Additionally concrete tests were undertaken to characterize concrete's compressive and tensile strength and its Young's modulus. Creep and shrinkage tests were conducted on a test specimen taken from the same concrete batch used for the instrumented structural parts. Fig. 3 shows a scheme of the instrumented frame. An integral structure like the frame displayed in this figure has its fixed point in the center and suffers the largest displacements at its free ends. Therefore, the instruments were located in the extreme columns, SM34 and SM38, and the joints. Throughout the campaign, the ambient temperature was measured on two levels: the first floor, N-1, which is located underground and the third floor, $\mathrm{N}+1$, which is located above ground. The measurements were obtained using LUFFT OPUS 10 (Lufft, Fellbach, Germany) weather stations with an operational temperature and humidity range of -40 to $+100^{\circ} \mathrm{C} / 0-100 \%$ relative humidity. The obtained data were compared with the temperature information provided by the weather station of the National Agency for Meteorology (AEMET, Madrid, Spain) located on the airfield, as shown in the temperature-time diagram in Fig. 5.

During the construction stage, from October 2002 until October 2003, the daily temperature cycles of the ambient temperature in the upper floors coincide with the temperature registered in the area, whereas the temperature in the lower part of the building already shows significantly lower variations. Unfortunately, there are gaps in this temperature registration stemming from data loss. The graph displays a complete measurement range of five years. The structure was taken into service in February 2006. The fragments of the ambient temperature measurements at level N-1 show that the ambient temperature inside the basement of the structure follows the seasonal cycles of the outside temperature but not its daily temperature cycles. Furthermore, the inside ambient temperature at this level remains above the monthly average outside temperature. In addition, the concrete's temperature was measured by means of type-J thermocouples, which were installed in the same locations as the strain gauges.

In Fig. 6, a comparison between the weather station on the first floor of the structure, N-1, and the thermocouples at the same level (T13-T16), is shown. While there are small differences at the beginning of the measurements, caused by direct radiation, the daily and temperature variations coincide after the structure had been taken into service. Fig. 7 shows the thermocouple measurements (T25-T28), at the third-floor level, $\mathrm{N}+1$, that perform similarly. The initial structural temperature measurements show an extreme peak caused by heat of hydration. This peak rapidly decreased and the thermocouples started registering the daily and seasonal temperature changes of the structure. The weather station again recorded slightly higher daily temperature variations that are attributable to direct radiation. Beyond the point at which the building's environmental systems were initialized the temperature began to stabilize at approximately $24^{\circ} \mathrm{C}$. This indicates that the structure will not undergo any temperature-induced displacements in the acclimatized areas during service life. The areas in the basement of the building, which are not air-conditioned and provide open access ramps, will follow temperature variations similar to the average monthly exterior temperature, as can be derived from Fig. 5 . 


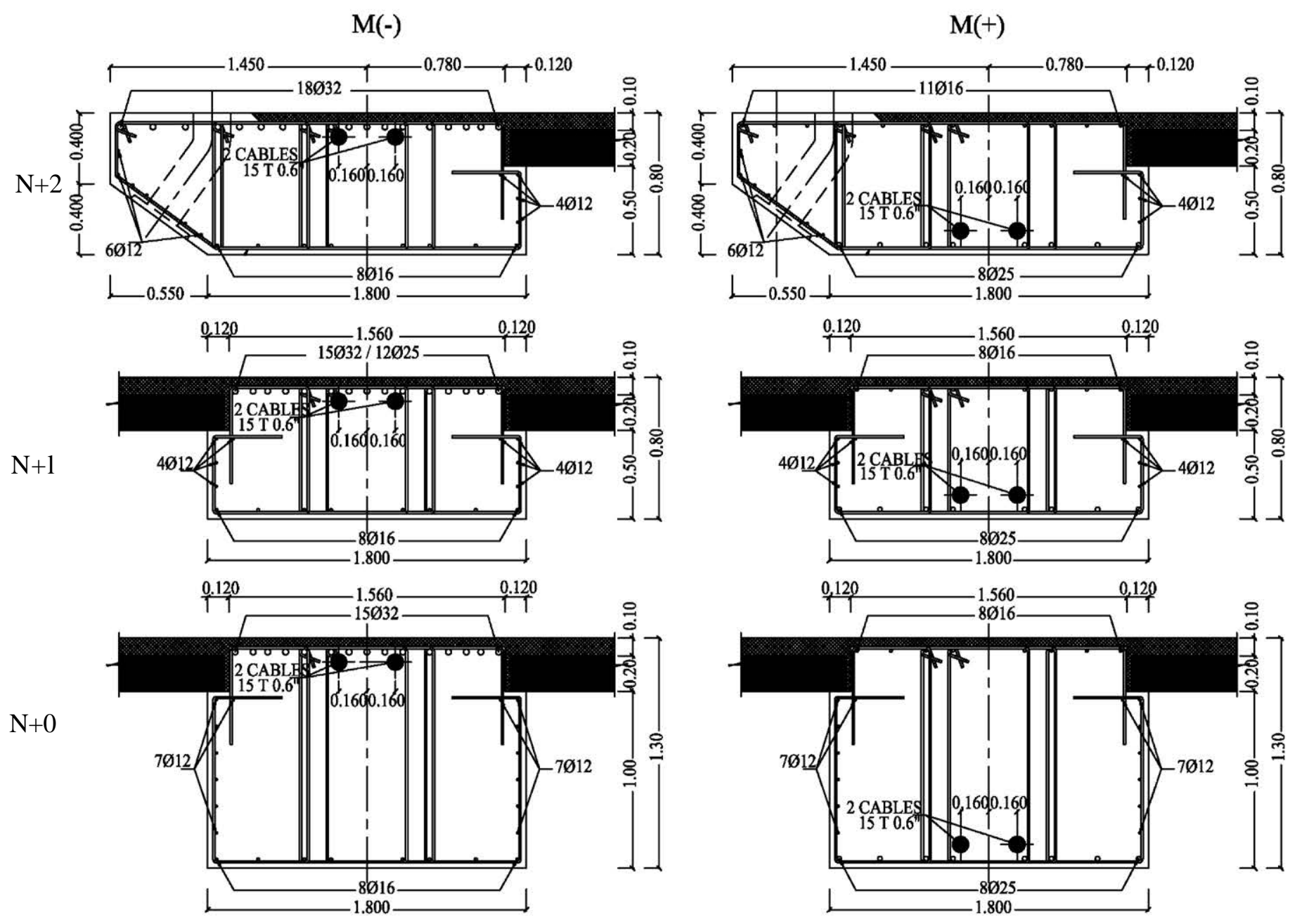

Fig. 4. Beams' cross-section geometries

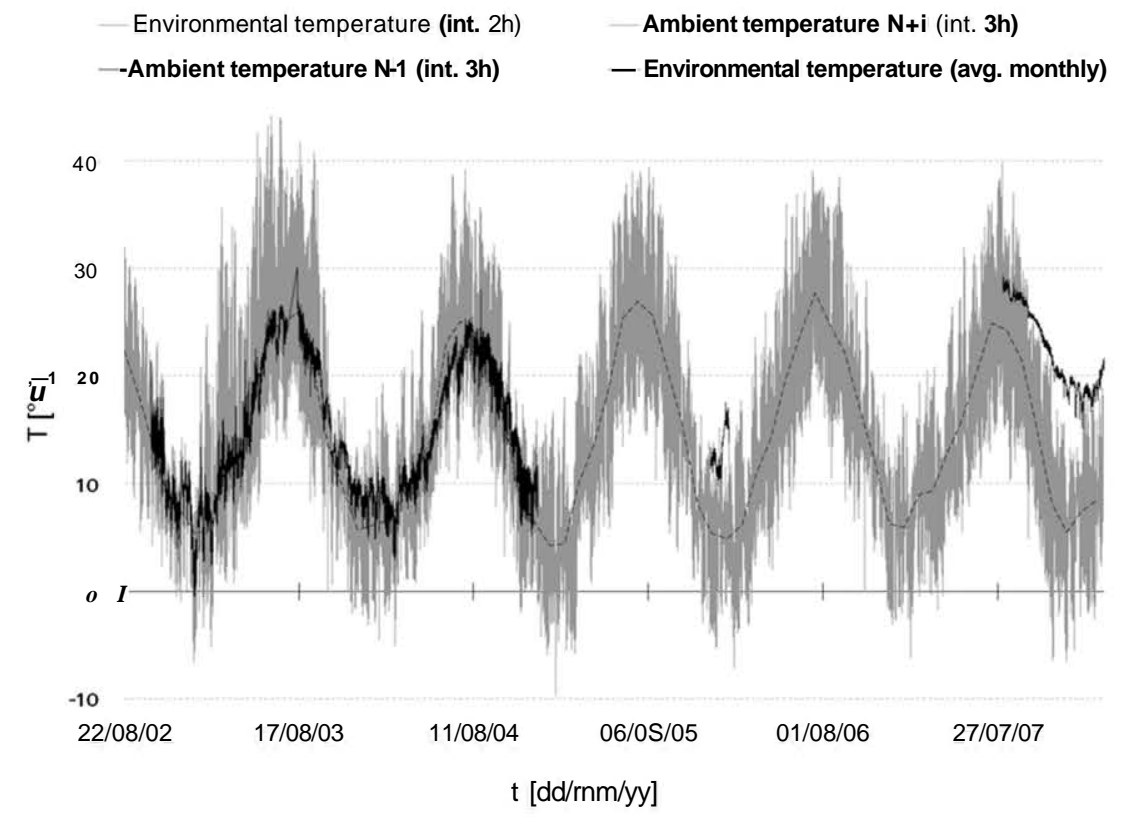

Fig. 5. Ambient temperature measurements in- and outside of the building 


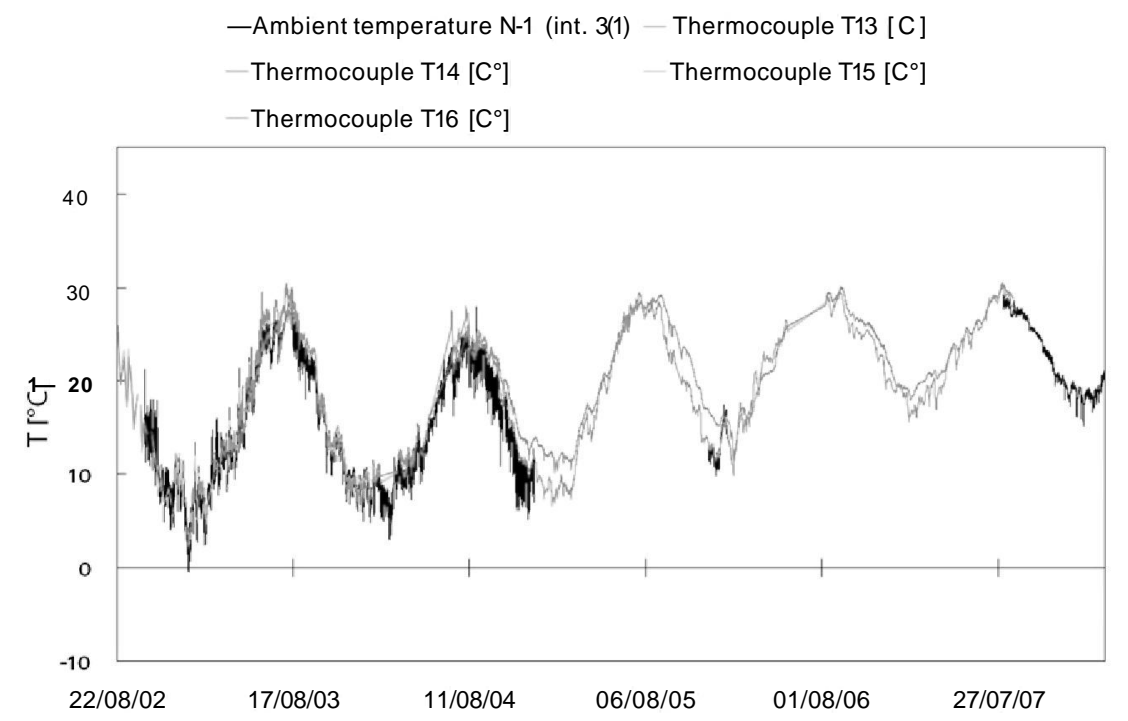

$\mathrm{t}[\mathrm{dd} / \mathrm{mm} / \mathrm{YY}]$

Fig. 6. Ambient and structural temperature measurements in the underground part of the structure

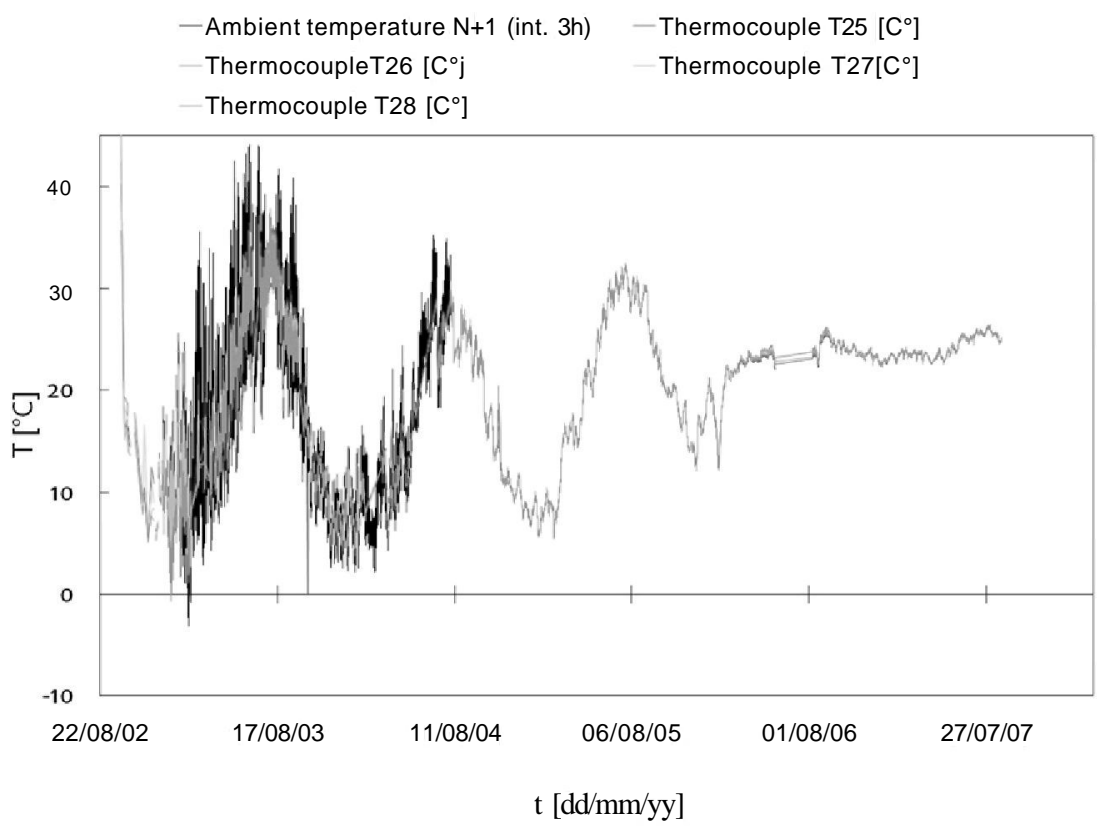

Fig. 7. Ambient and structural temperature measurements in the upper part of the structure

For the strain measurements in columns and beams, instrumented reinforcement bars, which provided the necessary bond length, were used. Four strain gauges in a full Wheatstone bridge configuration were installed in the center of each bar. The positioning of the instrumented bars on the structure is shown in Fig. 8. These instruments had to be installed prior to casting and their wires had to be guided through an embedded duct toward the datalogging system located at the base of the structure. Each instrumented bar was accompanied by superficial measurements with a hand-held mechanical strain gauge [demountable mechanical strain gauge (DEMEC)] as a means of comparison. The targets of the superficial measurements were glued onto the concrete's surface with epoxy adhesives after the formwork had been removed. Fig. 9 shows the deformed shape of a beam model of the instrumented frame undergoing a volume change without the presence of any vertical loading. The marks at the head of the extreme column, SM34 N-1, indicate the locations of the strain gauges whose data are presented in the diagram found in Fig. 10. The strains obtained from the embedded instrumented bars, registered in 3-h intervals, coincide well with the data obtained from the mechanical strain gauge. Finding such concordance between embedded and superficial measurements not only confirms the measured results, but also provides the possibility of being able to substitute data from one source to another in the event of data loss. 


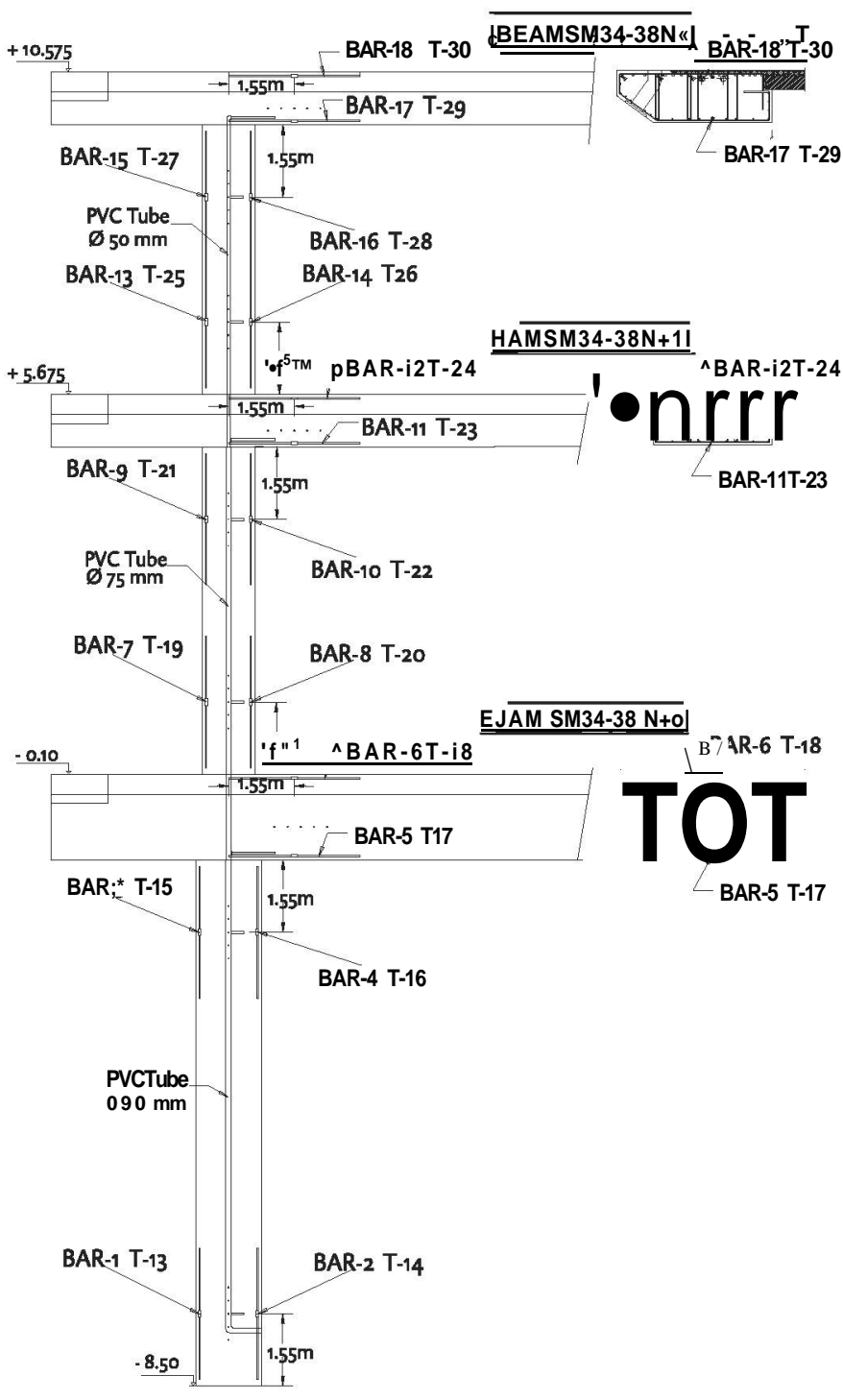

Fig. 8. Location of the strain gauges in the instrumented frame

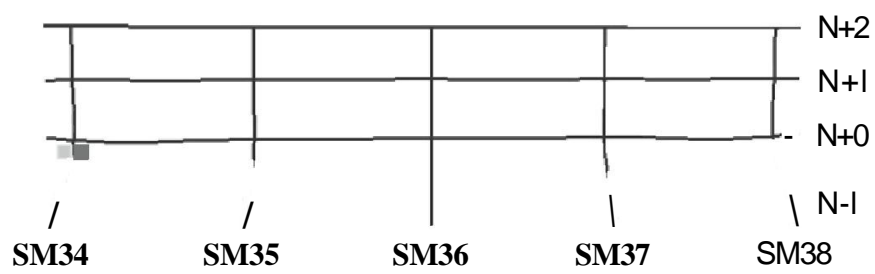

Fig. 9. Deformed frame

Hence, there are two main reasons for redundancy: verification and backup.

The diagram also shows that the structure apparently suffers from a shortening of the horizontal elements, as indicated by the superior compression monitored at the outward facing part of the column. From the strains measured in the extreme fibers of the column head's cross section, it is possible to derive the corresponding strain plane whose time-dependent evolution can be expressed in terms of curvature and strain at the centric fiber. Fig. 11 shows a curvaturetime diagram that represents the curvatures derived from the measurements at the bottom and the top of column N-1. The data confirms the behavior of the column, which is mainly influenced by a shortening of the horizontal element as schematically indicated on the left in Fig. 11. The curvature at the bottom gives negative results whereas the curvature at the column's head provides positive values. The graph also confirms the assumption of a symmetric displacement of the frame's ends, because the curvature values obtained from the discontinuous strain measurements of column SM38, located at the other extreme of the frame with inverted sign, coincide with the curvatures from column SM34.

Additionally, the structure's horizontal displacements were monitored by means of simple, robust, and cost-effective devices in the expansion joints between two frames, as shown in Fig. 12. Because the instrumentation depended on the adjacent frame, which was constructed with a delay of up to three months, there is a significant loss of initial data. Nevertheless, the possibility to correlate the displacements to the strain measurements turned out to be acceptable, as further comparisons had shown. In Fig. 13, the obtained displacement measurements are given. All three joints were built with an initial opening of $10 \mathrm{~mm}$. The obtained measurements start at openings of 19,20 , and $31 \mathrm{~mm}$, which indicate that at the time the joints were accessible to install the devices, all three joints had already undergone a significant variation in their opening. The trend lines indicate that temperature produces an acyclic effect around the remanent displacements produced by the long-term effects. Because of restrictions imposed by the owner of the building, the measurements in the two upper floors had to be terminated earlier than planned. The time to refers to the beginning of construction of the instrumented frame. The measurements in the beam of the first level, $\mathrm{N}+0$, were continued throughout the entire monitoring period.

\section{Discussion of the Results}

The partial post-tensioning of the frame's beams maintains their cross sections in an uncracked state under quasi-permanent loading. The effect of an imposed deformation consequently superimposes and the resulting strain at the reference fiber is the sum of prestressing, shrinkage, and creep, as shown in Fig. 14. Thus, the total displacement of a cross beam can be derived from its strain measurements, to which the temperature component must be added and then multiplied by its free length (which can be assumed as half of its overall length). A comparison of the displacement obtained from the strain measurements in beam SM34-38 N+0 and the displacement measured in the corresponding joint is shown in Fig. 15 in a displacement-time diagram. The two measurements show good agreement. The slight offset between both curves could be a result of increasing creep and shrinkage effects from the adjacent frame that had not been monitored, and therefore, could not be deducted from the displayed data. The comparison of these measurements simply shows the ability of the designed instrumentation to capture the movement of the structures, under the influence of imposed deformations, using different devices.

An analysis to predict the shortening of the beams resulting from creep and shrinkage according to CEN (2004) was conducted and compared with the measured displacements. During this analysis, each beam was represented by a single cross section based on standard design materials and loaded with the corresponding prestressing forces. Temperature effects were omitted for the two upper beams because they are located in a completely air-conditioned environment. The temperature variations occurring to the lower beam that are attributable to its location in the ceiling of the underground floor superimpose directly upon the long-term effects. In 


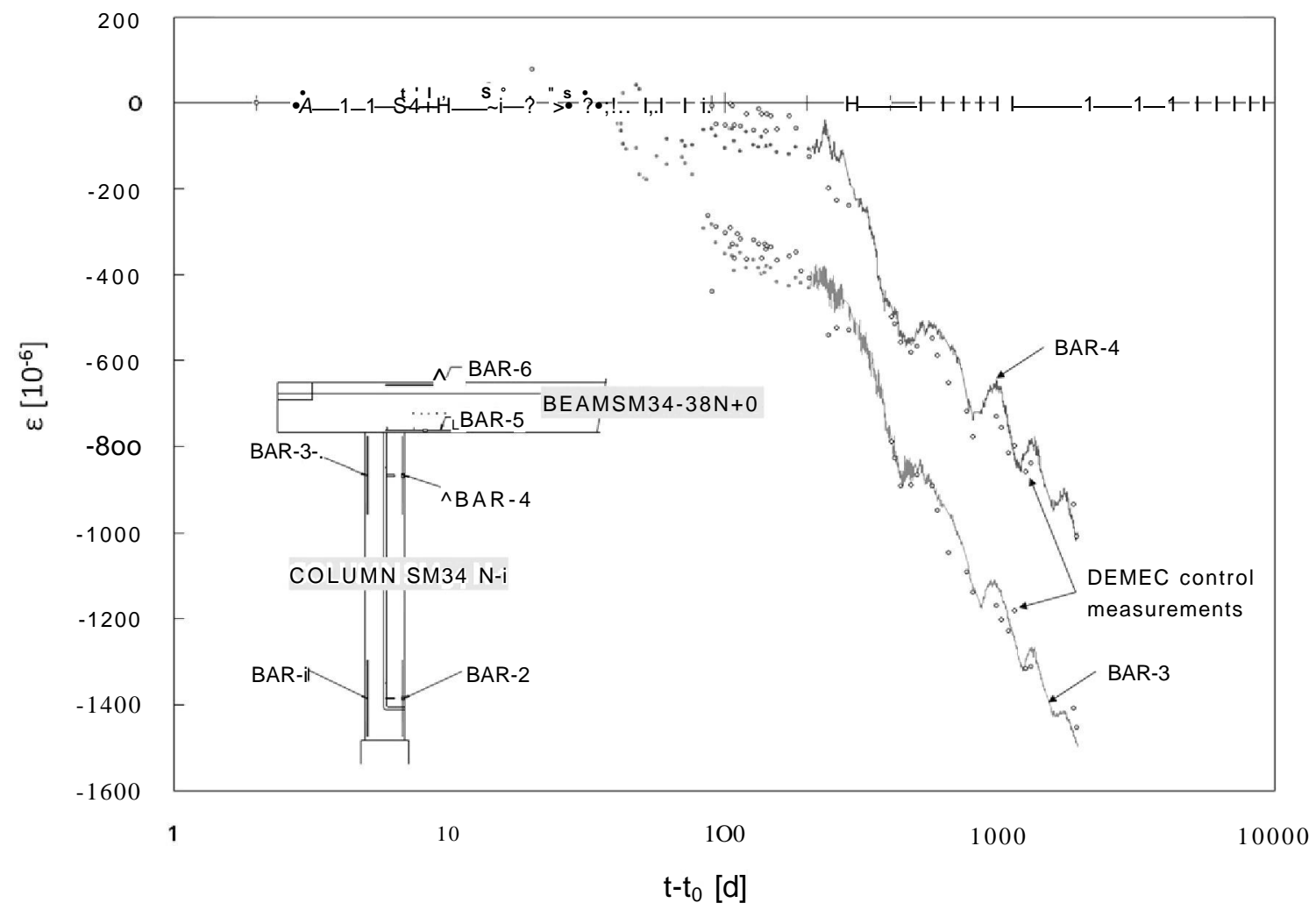

Fig. 10. Continuous and discontinuous strain measurements at column head SM34 N-1

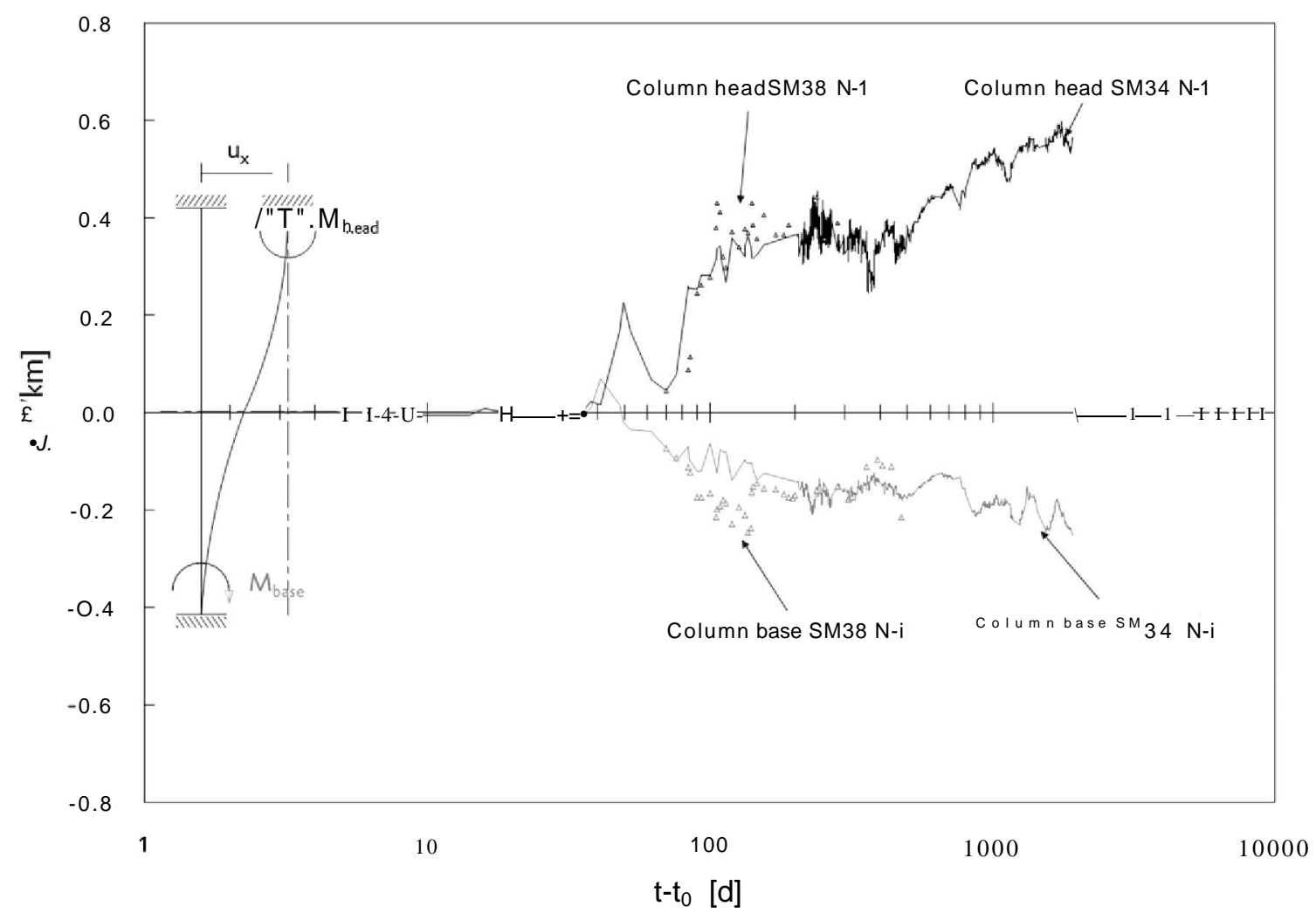

Fig. 11. Curvatures at column head and base SM38 N-1 and SM34 N-1 
Fig. 6, it can be seen that after the building was finished and put into service, the minimum temperature was approximately $T^{\wedge}=15^{\circ} \mathrm{C}$ and that the maximum temperature was approximately $30^{\circ} \mathrm{C}$. Assuming an average inside temperature of $20^{\circ} \mathrm{C}$, the unfavorable temperature effect of cooling was determined to be $-5^{\circ} \mathrm{C}$. The analysis also considers an average relative humidity of $\mathrm{RH}=65 \%$, which was derived from the local humidity measurements. Curing period and time of prestressing were $t_{s}=7 \mathrm{~d}$ and $t_{0}=7 \mathrm{~d}$, respectively. The concrete considered for all cross sections had a cylindrical compression strength of $/_{\mathrm{c}} \mathrm{t}=40 \mathrm{MPa}$. The values of each cross section's effective thickness and its stresses induced by prestressing are given in Fig. 16.

The cross sections are of similar effective thickness, e, but the slightly higher value of cross section $\mathrm{N}+0$ is leading to a minor

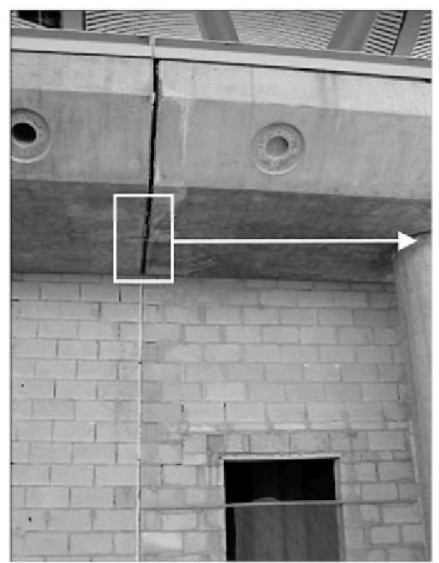

(a)

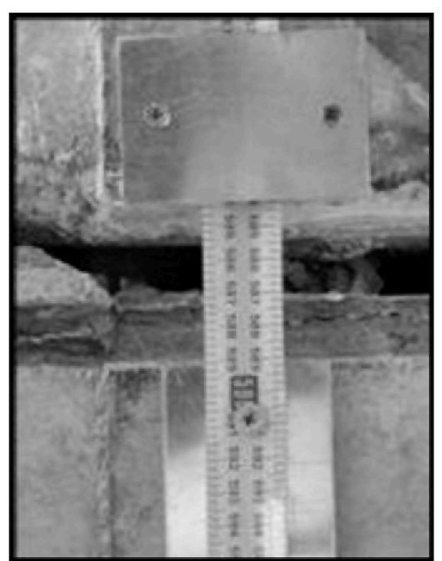

(b)
Fig. 12. Displacement measurements at the expansion joints (photographs by Tobias Petschke) deceleration of the predicted shrinkage development as shown in Fig. 17. The predicted creep strain curves of the cross sections are shown in Fig. 18, considering exclusively the applied prestressing. Cross-section $\mathrm{N}+1$ develops the highest creep strains because of its smaller cross-section area. In Fig. 19, the curves obtained from the analysis considering creep, shrinkage and, in the case of beam $\mathrm{N}+0$, temperature, are compared with the measurements and good agreement could be found. In case of the second floor's cross beam, $\mathrm{N}+1$, the values fall below the initial shortening, but fit rather well with the long-term deformations measured. The predictions for the beams of the first floor, $\mathrm{N}+0$, and the third floor, $\mathrm{N}+2$, exceed the long-term results. The shear connectors in the joints were tested to function under service load even with a maximum joint opening of $70 \mathrm{~mm}$. The prediction of the frame's horizontal beam displacements had shown that the maximum expected shortening was approximately $27 \mathrm{~mm}$. Therefore, the maximum joint opening of two large adjacent frames could be expected to be $27 \times 2+10 \mathrm{~mm}=64 \mathrm{~mm}$. However, in general this maximum opening will not be reached because of a compensation of the initial elastic creep strains during the construction process.

In a linear frame model, produced with the software SOFiSTiK (2009), the structural behavior of the frame was analyzed. On site, cracks were found in the extreme columns of all three floor

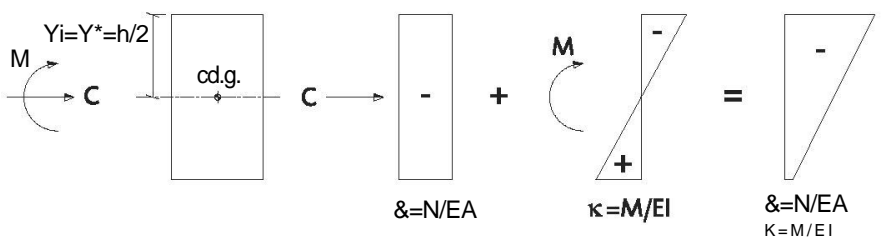

Fig. 14. Effect of uniform imposed deformations on uncracked cross sections

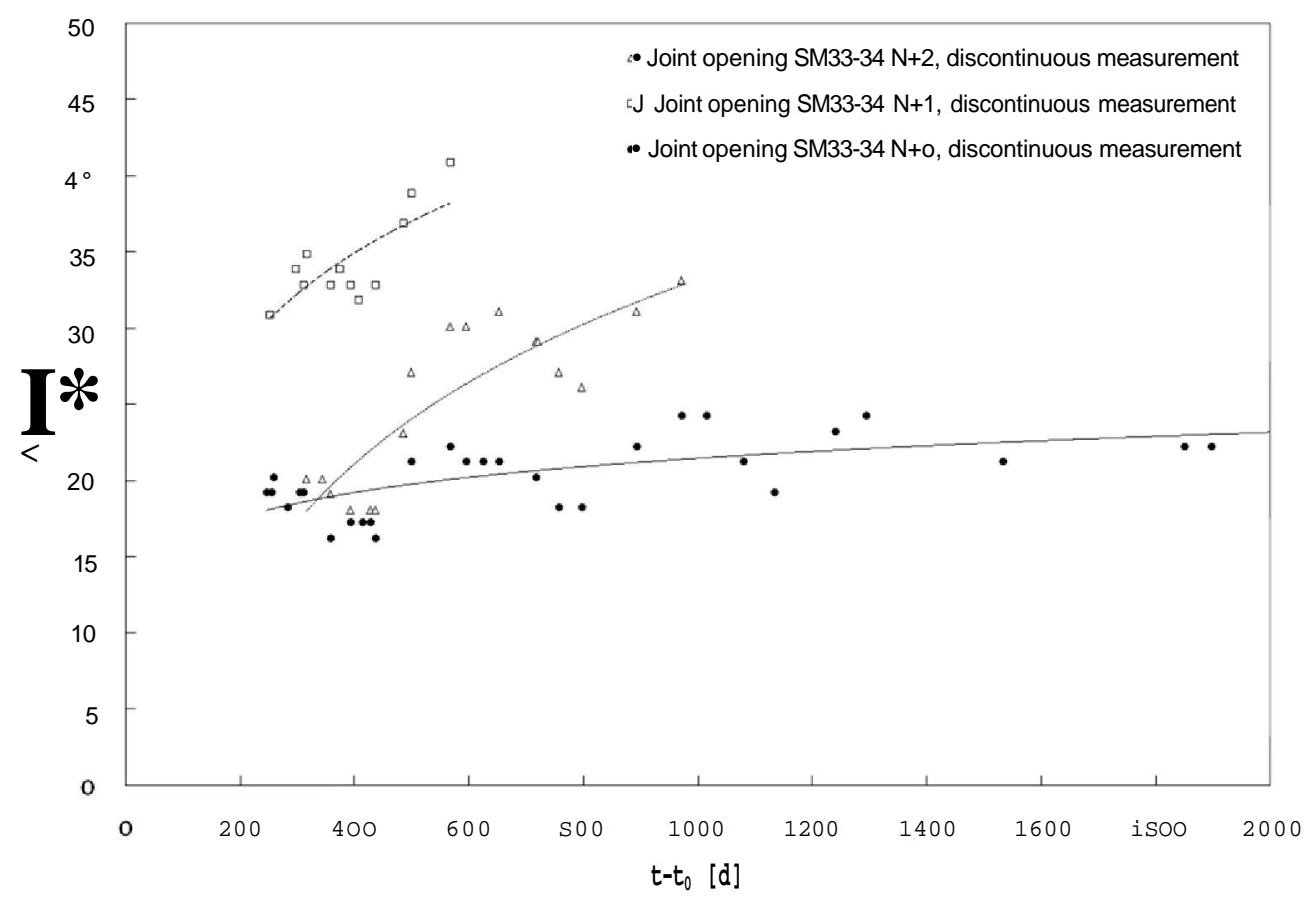

Fig. 13. Variation of the measured joint openings 


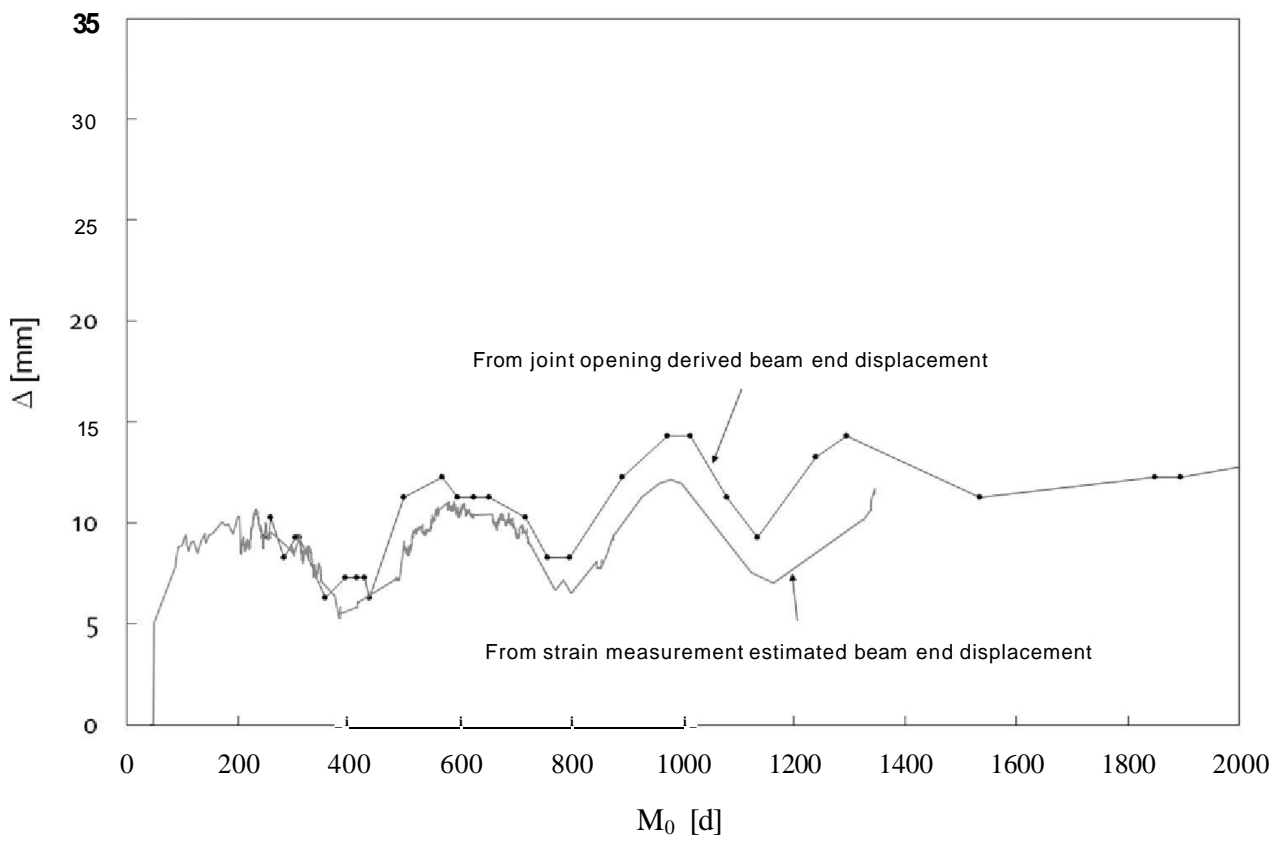

Fig. 15. Comparison of measured displacement and horizontal displacement derived from measured strains of beam SM34-38 N+0

levels. The cracks of the columns in the underground floor closed again during the further construction process because of increasing upload. One aspect of the analysis was to determine when the first cracks were formed and thus, it could be verified that the columns cracked based on the column head displacement introduced by prestressing of the beams. In Table 4, the column sections with their corresponding forces and crack-width results are shown.

The influence of the columns' stiffness reduction from cracking is insignificant, because the beam's axial stiffness component is approximately 76 times higher than the columns' bending stiffness. The large axial stiffness component of the beams leads to an almost free expansion and contraction. Therefore, any column interaction onto the horizontal displacements can be seen as remarkably small.

\section{Conclusions}

Throughout this research a measurement campaign had been developed to monitor the effects of imposed deformations onto a monolithic integral frame structure. It could be shown that it is vital to provide redundant measurements to reconstruct or substitute for possible data gaps that occurred from malfunctioning devices or loss of such devices despite security measures taken on site. The instrument configuration used had shown an acceptable robustness and provided reliable data. The measurements of the joint openings had shown that even with a very simple and cost-effective measurement device, a reliable amount of data could be obtained. (However, it is advisable to use embedded devices to avoid visible instruments on any surface.) The temperature measurements had shown that the maximum daily temperature cycles, measured by the environmental weather station, are only affecting the structure during the very beginning of the construction. As construction progresses, the amplitudes of these cycles soften significantly, resulting in exclusively seasonal variations in the non-air-conditioned

\begin{tabular}{|c|c|c|c|}
\hline Beam SM34-38 & Cross section & $e[\mathrm{~mm}]$ & $a_{P}[\mathrm{MPa}]$ \\
\hline $\mathbf{N}+2$ & & 901 & -3.62 \\
\hline $\mathbf{N}+\mathbf{l}$ & & 921 & -4.64 \\
\hline $\mathbf{N}+\mathbf{0}$ & & 1152 & -2.73 \\
\hline
\end{tabular}

Fig. 16. Cross sections considered during the analysis

areas of the building such as the first floor with its open access ramps. The temperature in the air-conditioned areas stabilizes at approximately $24^{\circ} \mathrm{C}$. These results indicate that the imposed deformations caused by temperature are only relevant during a long-term prediction in the lower part of the building, while the upper structure solely undergoes a length reduction caused by creep and shrinkage.

The analysis of the measured data had shown that there is substantial correspondence between the data obtained from the embedded instrumented bars and the superficial mechanical strain gauge measurements. It could also be shown that there is good agreement in the redundant measurements, such as the comparison of displacement measurements in the expansion joint of the first floor beam and its displacement derived from strain measurements.

The stiffness comparison between beams and columns had shown that the restraining effects of the column onto the free displacement of the beams are insignificantly small, and that the prediction of the joint openings, by means of a simple cross-section analysis, is a sufficiently accurate procedure. 


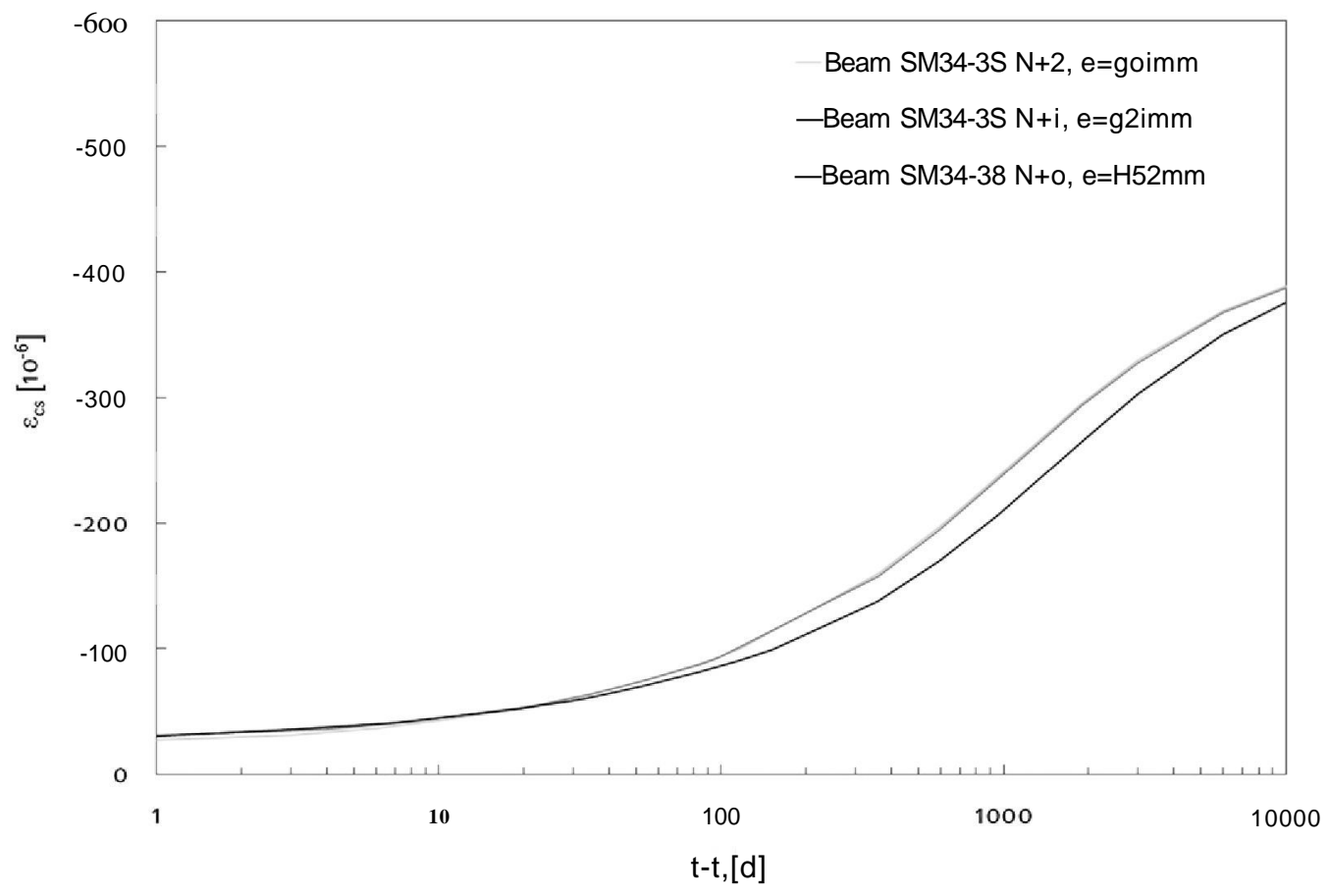

Fig. 17. Shrinkage prediction for the three different analyzed cross sections

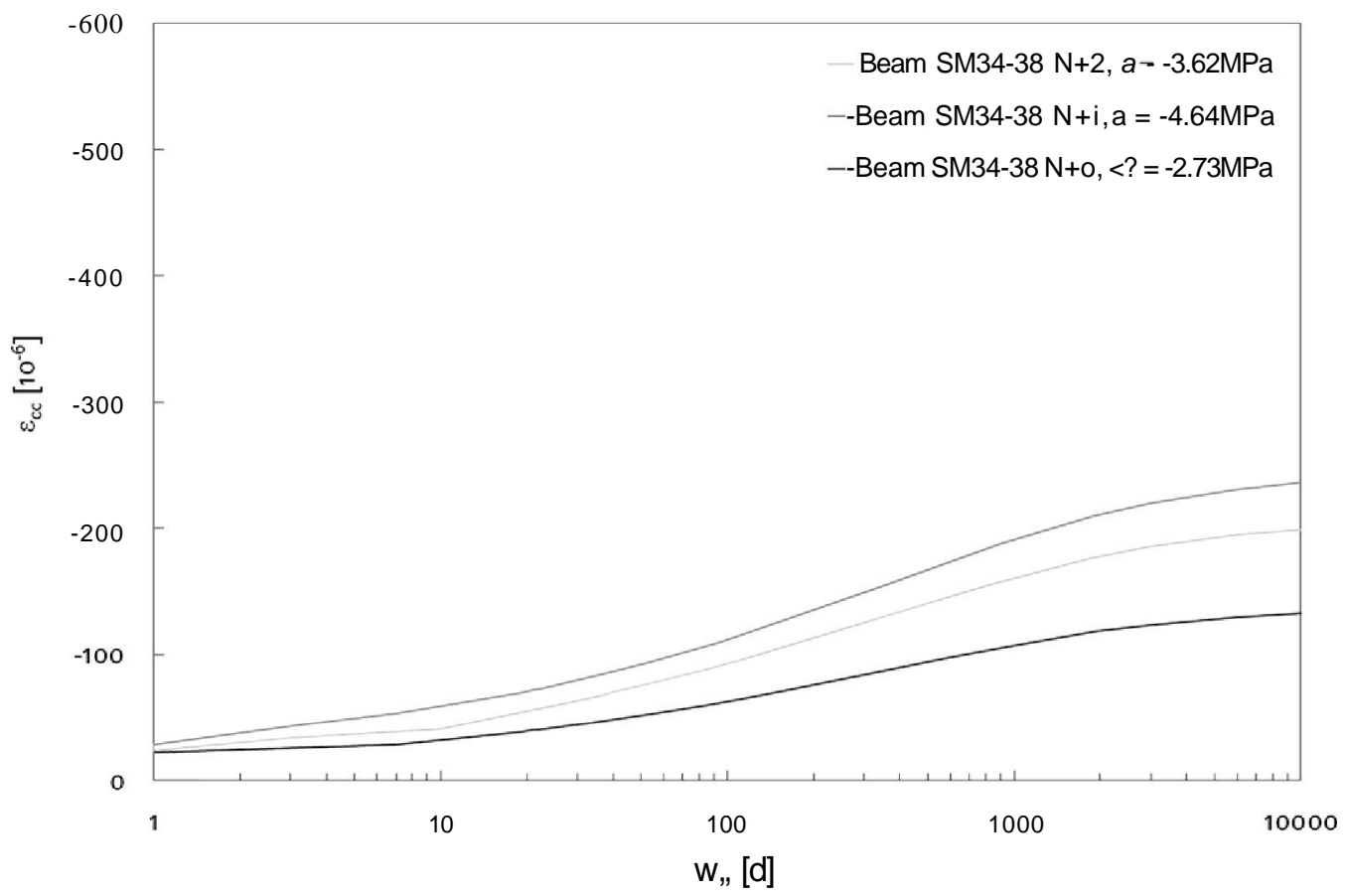

Fig. 18. Creep prediction for the three different analyzed cross sections

\section{Acknowledgments}

The work presented herein was funded by the Ministry of Public Works and Transport. It was only possible to establish and execute the instrumentation with the thorough support of the owner AENA, the contractor DRAG ADOS, and the consulting company FHECOR. Thanks are given to Eduardo Monzon of the company Promedy, Protección, Medición y Analysis S.L. and to Tomás Fariñas of Grupo de Medidas Ibérica S.L., both of whom provided extensive support on the supplied measuring devices. The authors also thank Jose Torrico for his valuable input throughout this study, as well as Jesús Sánches Ligero of DRAGADOS and Jesús Mendiluce of AENA for their assistance and support. 


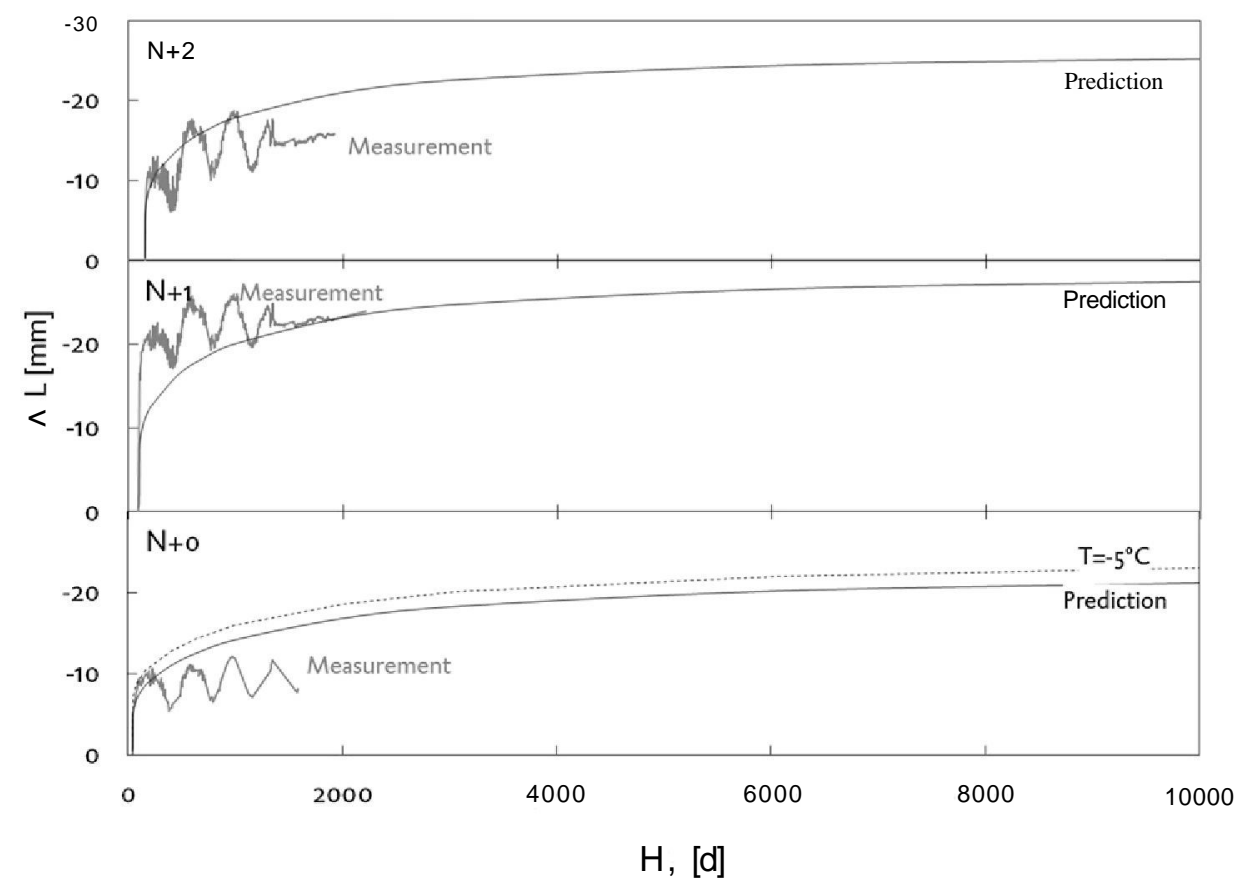

Fig. 19. Displacement comparison: prediction and measurements

Table 4. Crack Width Results for Column SM34

\begin{tabular}{lcccrr}
\hline Column & Level & Section & Construction phase & $\mathrm{N}(\mathrm{kN})$ & $\mathrm{M}(\mathrm{kN} / \mathrm{m})$ \\
\hline SM34 & $\mathrm{N}-1$ & Base & Prestressing beam N+0 & -740 & -214 \\
SM34 & $\mathrm{N}-1$ & Head & Prestressing beam N+0 & -607 & 85 \\
SM34 & $\mathrm{N}+0$ & Base & Prestressing beam N+1 & -414 & -158 \\
SM34 & $\mathrm{N}+0$ & Head & Prestressing beam N+1 & -355 & 0.02 \\
SM34 & $\mathrm{N}+1$ & Base & Prestressing beam N+2 & -519 & 0.01 \\
SM34 & $\mathrm{N}+1$ & Head & Prestressing beam N+2 & -469 & -170 \\
\hline
\end{tabular}

\section{Notation}

The following symbols are used in this paper:

$e=$ effective thickness $(\mathrm{mm})$;

$T \cdot \bullet=$ temperature $\left({ }^{\circ} \mathrm{C}\right)$;

$t=$ time

$t_{s}=$ time of curing;

to $=$ time of loading or construction;

$u_{\mathrm{x}}=$ horizontal column head displacement;

$\mathrm{A}=$ joint opening $(\mathrm{mm})$

$A L=$ horizontal overall beam displacement $(\mathrm{mm})$;

$£=$ measured strain $\left(10^{-6}\right)$;

$f_{\mathrm{cc}}=$ creep strain $\left(10 \sim^{6}\right)$;

$f c \underline{s}=$ shrinkage strain $\left(10 \sim^{6}\right)$;

$\kappa=$ curvature $(1 / \mathrm{km}) ;$ and

$\sigma_{\mathrm{p}}=$ prestressing-induced stresses $(\mathrm{MPa})$.

\section{References}

Aboumoussa, W., and Iskander, M. (2003). "Thermal movements in concrete: Case study of multistory underground car park." /. Mater. Civ. Eng., 15(6), 545-553.

American Concrete Institute (ACI). (2008). Manual of concrete practice, Farmington Hills, MI.
Camara, J. (1988). "Comportamento em serviço de estructuras de betao armado e pré-esforcado." Ph.D. dissertation, Univ. Técnica de Lisboa, Lisboa, Portugal (in Portuguese).

European Committee for Standardization (CEN). (2004). "Design of concrete structures, part 1-1: General rules and rules for buildings." Eurocode 2, Brussels, Belgium.

Forth, J., Brooks, J., and Bingel, P. (2003). "Movement in a seven storey reinforced concrete frame." Proc, Inst. Civil Eng. Struct. Build., 156(2), 131-140.

Hock, B., Schäfer, K., and Schlaich, J. (1986). Fugen und aussteifungen in stahlbetonskelettbauten, Vol. 368, Deutscher Ausschuss für Stahlbeton (DAfStb), Berlin (in German).

Iqbal, M. (2007). "Thermal movements in parking structures." Struct. J., 104(5), 542-548

Iskander, M., Aboumoussa, W., and Gouvin, P. (2001). "Instrumentation and monitoring of a distressed multistory underground parking garage." 1. Perform. Constr. Facil, 15(3), 115-123.

Koch, R., and Plötzel, M. (2001). "Erkenntnisse aus messungen an der fugenlosen briicke iiber das Nesenbachtal in Stuttgart." Beton-und Stahlbetonbau, Ernst \& Sohn Verlag, Berlin, 96(10), 670-678 (in German).

Ministerio de Vivienda. (2006). Código técnico de la edificación, Technical Building Code (CTE), Madrid, Spain (in Spanish).

Pfeiffer, U. (2004). "Die nichtlineare berechnung ebener rahmen aus stahloder spannbeton mit beriicksichtigung der durch aufreissen bedingten achsendehnung." Ph.D. dissertation, Technische Univ. Hamburg, Hamburg, Germany (in German).

SOFiSTiK. (2009). SOFiSTiK FEM: Benutzerhandbuch 11.25-25, SOFISTIK AG, Oberschleissheim, Germany (in German). 